\title{
REDE GLOBO DE TELEVISÃo NO TERRITÓRIO BRASILEIRO: SISTEMA DE EMISSORAS AFILIADAS
}

Eliane Regina Munhoz*

Resumo: O sistema de emissoras afiliadas da Rede Globo de Televisão consolidou-se no Brasil na década de 1970, já no período técnico, científico e informacional, com a intensificação de densidades técnicas, informacionais e normativas no território nacional. A empresa, ao organizar este sistema, cria uma divisão territorial do trabalho que transforma as afiliadas em unidades de produção de informações para a sede, enquanto ela produz a maior parte da programação que é transmitida pelas afiliadas. A existência de uma tecnosfera e de uma psicosfera cria as condições para que este sistema funcione com uma alta capilaridade territorial e se imponha verticalmente nos lugares.

Palavras-chave: território brasileiro, Rede Globo de Televisão, informação, comunicação, lugar.

\section{TELEVISION IN BRAZILIAN TERRITORY: THE SYSTEM OF BROADCAST AFFILIATED OF REDE GLOBO TELEVISION}

\begin{abstract}
The system of broadcast affiliated of Rede Globo Television consolidated in the Brazil in the 1970s, in the scientific and technical information era, with the intensification of technical, informational and normative densities within the national territory. The company, in order to organize this system, established a territorial division of labor that transforms the affiliates in the production units of information to headquarters, while it produces the bulk of programming that is transmitted by affiliates. The existence of a technosfera and a psichosfera creates the conditions so that this system operates with a high territorial capillarity and vertically imposes its transmition everywhere.
\end{abstract}

Keywords: Brazilian territory, Rede Globo Television, information, communication, place.

\section{Introdução}

\section{Após a Segunda Guerra Mundial,} como parte do processo de modernização do território brasileiro, teve início a instalação, comandada por ações do Estado, de uma infraestrutura de comunicação. A partir da instalação de redes de suporte, este meio técnico possibilitou encaminhar e direcionar fluxos, que foram utilizados pelas redes de serviço (transmissão de dados, rede telefônica, redes de videoconferência) da
Região Concentrada ${ }^{1}$ em direção às demais regiões brasileiras (DIAS, 1996).

\author{
Usando essas redes de suporte, a \\ partir de São Paulo e do Rio de Janeiro,
}

\footnotetext{
1 "Trata-se de uma área contínua, onde uma divisão do trabalho mais intensa que no resto do país garante a presença conjunta das variáveis mais modernas - uma modernização generalizada - ao passo que, no resto do país, a modernização é seletiva, mesmo naquelas manchas ou pontos cada vez mais extensos e numerosos onde estão presentes grandes capitais, tecnologias de ponta e modelos elaborados de organização" (SANTOS, 2005 , p. 42-43). Refere-se a uma mancha do meio técnico-científico e informacional compreendida pelos estados de São Paulo, Rio de Janeiro, Minas Gerais, Espírito Santo, Paraná, Santa Catarina e Rio Grande do Sul.
} 
emissoras brasileiras ${ }^{2}$ como a Rede Globo de Televisão expandiram gradativamente sua programação para o território ${ }^{3}$ a cada inovação técnica viabilizada economicamente, conformando redes de serviços. "A instalação da base técnica e econômica dos processos modernos de comunicação inscreve-se em características de reorganização da estrutura produtiva do país, iniciada nos anos 60 sob o regime militar" (RIBEIRO, 1991, p. 46). Assim beneficiam-se as empresas privadas com a rede nacional de microondas, entre 1957 e 1983; a partir de 1985 com os satélites e na década de 1990 com os enlaces locais de fibra ótica. ${ }^{4}$ Assim:

O sistema moderno de comunicação no Brasil, em sua face política, pode ser compreendido como parte do aparelho institucional criado para o desenvolvimento de estratégias de controle do território nacional e, em sua face econômica, como elo articulador e agilizador de mercados (RIBEIRO, 1991, p. 46).

\section{A densidade técnica compreende}

objetos e sistemas técnicos implantados num determinado lugar, "dispostos para atender

\footnotetext{
2 "Os serviços de televisão podem ser classificados quanto ao âmbito de cobertura (internacional, nacional, regional e local), ao meio de emissão (ondas hertzianas terrestres, a cabo, satélite e MMDS), ao nível de comunicação (unidirecional e bidirecional e (ou) interativa), e ao sistema de transmissão (analógico e digital)" (SCORSIM, 2007 , p. 72). No caso da Rede Globo de Televisão, configura-se uma rede nacional, que utiliza tanto ondas hertzianas como satélites para suas emissões, de forma unidirecional, através de sistema analógico e digital (apenas para alguns lugares).

${ }^{3}$ Segundo Santos (2002, p. 16-19), para conhecer sistematicamente a realidade é necessário "um tratamento analítico desse seu aspecto fundamental que é o território (o território usado, o uso do território)", ou seja, "o território são formas, mas o território usado são objetos e ações, sinônimo de espaço humano, espaço habitado".

4 "Em 1987, as ligações em microondas atingiam $22.562 \mathrm{~km}$ de extensão, e trinta estações terrenas, receptoras e emissoras de sinais de telecomunicação por satélite, estavam instaladas" (DIAS, 1996, p. 125).
}

prontamente às intenções dos que os conceberam e produziram". Já "a densidade informacional deriva, em parte, da densidade técnica", e revela "o grau de exterioridade do lugar e a realização de sua propensão a entrar em relação com outros lugares, privilegiando setores e atores" (SANTOS, 1996, p. 205). A densidade comunicacional é a possibilidade que existe de as demais densidades gerarem significado, organicamente.

Desta forma, as densidades técnica e informacional estão associadas às verticalidades nos lugares, enquanto que a densidade comunicacional, inseparável das outras densidades, reforça a criação de horizontalidades.

Os meios ${ }^{5}$ comunicação de amplo alcance $^{6}$ são criadores de verticalidades, ao emitirem informação de um centro para vários pontos, vários lugares, ao mesmo tempo em que também entram na trama das horizontalidades, através do processo de emissão-recepção das informações, mensagens, códigos, ideias, externos a eles.

\footnotetext{
5 "Em latim, 'meio' se diz medium e, no plural, 'meios' se diz media. Os primeiros teóricos dos meios de comunicação empregaram a palavra latina media. Como eram teóricos de língua inglesa, diziam: mass media, isto é os meios de massa. A pronúncia, em inglês, do latim media é 'mídia'. Quando os teóricos da língua inglesa dizem 'the media', estão dizendo: 'os meios'. Por apropriação da terminologia desses teóricos no Brasil, a palavra 'mídia' passou a ser empregada como se fosse uma palavra feminina no singular 'a mídia'"' (CHAUÍ, 2006, p. 35).

6 Ortiz considera que "analiticamente, é difícil conceber uma sociedade em termos de massa" (2000, p. 95) e o termo "comunicação de massa" tem limitações. Denominamos meios de comunicação o que se refere aos veículos utilizados para propagar imagens, textos, sons, ideias (televisão, rádio, jornal, revista, internet etc.) e, provisoriamente, meios de comunicação de amplo alcance para os que conseguem atingir com suas ações grandes extensões, como acontece com a Rede Globo de Televisão no Brasil.
} 
Ocorre que com a difusão do meio técnico científico informacional, como possibilidade para todos e como realidade para alguns, a informação, produzida centralizadamente, se confunde com o acesso aos meios de comunicação.

O acesso aos meios de comunicação foi ampliado nas últimas décadas com o aumento da densidade técnica. Os meios são garantidos tecnicamente, mas a comunicação no sentido amplo de dispositivo que garante coesão política e cultural (MARTÍN-BARBERO, 2003) se efetiva de forma residual. A comunicação alinha-se às necessidades da modernização e reafirma a ideologia da Modernidade.

A noção de informação como processo é substituída pela informação apenas como produto e como mercadoria (FERRARA, 2002). ${ }^{7}$ Consideramos entretanto que a informação deve integrar organicamente o processo de comunicação.

Essa informação mercadoria, oferecida pelos meios de comunicação de amplo alcance, integra um contexto mais amplo da informação no meio geográfico contemporâneo.

A geógrafa Adriana Maria Bernardes da Silva, ao analisar o papel das empresas de consultoria como parte dos circuitos produtivos contemporâneos, revela o papel da informação estratégica para as "poderosas corporações globais":

\footnotetext{
7 "A informação instantânea expõe, com toda a força, a dimensão tecnológica da sua produção e expansão levando-nos a acreditar, num raciocínio precipitado e superficial, que o acesso a ela é automaticamente comandado à distância na geração do produto e do processo, igualando todas as aldeias do globo numa única comunidade humana, social e cultural" (FERRARA, 2002, p. 165).
}

A informação produzida nesse contexto de globalização se define como um recurso estratégico, utilizado seletiva e hierarquicamente. Energia da aceleração contemporânea, dessa busca por fluidez, a informação torna-se, então, o próprio motor da nova divisão social e territorial do trabalho (SANTOS, 1996 apud SILVA, 2005, p. 144).

A atual produção e o uso da informação conferem ao meio geográfico a denominação de meio técnico, científico e informacional, proposta por Santos (1996). Como a informação é uma variável central para a expansão do capitalismo mundial, os espaços nacionais são submetidos a uma divisão territorial do trabalho comandada em grande parte por ela.

Diante deste contexto da informação e da comunicação no meio geográfico atual, investigamos a empresa Rede Globo de Televisão, que veicula uma programação nacional $^{8}$ para $99,43 \%$ dos municípios do território brasileiro através de um sistema com emissoras afiliadas.

Este sistema de afiliadas, que se implantou utilizando as redes de suporte oferecidas pelo Estado, através de normas rígidas, estabelece no território uma solidariedade organizacional. A Rede Globo de Televisão insere-se na conceituação de Milton Santos sobre as novas corporações que promovem fluidez territorial ${ }^{9}$ através de suas ações:

\footnotetext{
8 Trata-se de programas televisivos produzidos pelas emissoras próprias do Rio de Janeiro e de São Paulo, destacando-se as novelas e minisséries, o Jornal Nacional, filmes, desenhos animados, programas de auditório, esportivos, rurais, etc. Compreende cerca de $70 \%$ da programação da emissora.

9 "Pode-se distinguir entre uma fluidez virtual e uma fluidez efetiva do território. A fluidez virtual será medida em função da presença dos
} 
A eficácia das grandes empresas vem de sua presença em lugares estratégicos do espaço total, pontos escolhidos por elas mesmas, de onde exercem sua ação sobre outros pontos ou zonas, diretamente ou por intermédio de outras firmas (SANTOS, 2005, p. 127).

Para que esta empresa se estabelecesse no território brasileiro como uma rede de televisão nacional, adotou-se o modelo criado pela rede de televisão estadunidense National Broadcasting Company (NBC), firmando contrato com emissoras locais já existentes e com emissoras criadas para ser afiliadas da Rede Globo de Televisão. Tais emissoras serviriam de base para a produção de notícias - já que a produção das afiliadas é, contratualmente, cedida à Rede Globo de Televisão para que ela, se julgar necessário, promova sua veiculação nacional ou internacional. Além disso, as afiliadas serviriam para retransmitir a programação nacional, e para produzir o conteúdo local. A Rede Globo de Televisão veicula no território, através da capilaridade gerada por suas 121 emissoras próprias e afiliadas $^{10}$ (Mapa 1), a programação nacional produzida no eixo Rio de Janeiro/São Paulo.

Nos debruçamos sobre esta territorialidade das ações da Rede Globo de Televisão, a fim de compreender o sistema

respectivos sistemas de engenharia. No entanto, o número e a densidade das vias podem não ser correspondidos pela frequência e densidade do seu uso. A presença dos meios produz a fluidez virtual, enquanto a fluidez efetiva é dada pelo uso efetivo dessas vias" (SANTOS; SILVEIRA, 2001, p. 262).

10 As emissoras próprias estão sob o controle acionário da Rede Globo de Televisão. Já as emissoras afiliadas, pertencentes a redes regionais ou não, são controladas por empresários de comunicação e em alguns casos contam com pessoas da família Marinho (Organizações Globo) entre seus acionistas. Ambas pleiteiam a concessão para utilização do espectro eletromagnético perante o Ministério das Comunicações, para transmitir seus sinais de televisão por radiodifusão (via hertziana). de emissoras afiliadas através de uma divisão territorial do trabalho criada pela empresa, ${ }^{11}$ que produz desde o conteúdo nacional até o conteúdo local, reforçando centralidades, integrando eletronicamente o território e, principalmente, definindo um uso corporativo do território.

Para compreender o funcionamento do sistema de afiliadas, analisamos 0 processo de produção da programação local de quatro afiliadas da Rede Globo de Televisão no estado de São Paulo: TV TEM de Bauru, EPTV de Campinas, TV Fronteira Paulista de Presidente Prudente e TV Tribuna de Santos. As duas primeiras integram as principais redes de comunicação do estado e as demais são emissoras isoladas, não pertencentes às redes até o momento.

Focalizamos a produção dos conteúdos locais destas quatro emissoras afiliadas, a fim de verificar o que é produzido e quem produz, assim como o tempo e o espaço destinados a esta programação. Desta forma, pudemos checar a representatividade dos lugares na programação da emissora, através da produção de conteúdo local. Poderíamos pensar que tal programação, ao ser anunciada pela Rede Globo de Televisão com o slogan "Globo, a gente se vê por aqui", afirma-se como representante oficial da cultura brasileira.

Partimos de uma concepção de
espaço geográfico que pressupõe a
indissociabilidade entre os sistemas de objetos e os sistemas de ações (SANTOS, 1996). Na pesquisa, os sistemas de objetos

\footnotetext{
11 "Essa divisão territorial do trabalho cria uma hierarquia entre lugares e, segundo a sua distribuição espacial, redefine a capacidade de agir de pessoas, firmas e instituições" (SANTOS, 1996, p. 108).
} 
são analisados com a instalação de sistemas de engenharia, uma tecnosfera ${ }^{12}$ utilizada pela Rede Globo de Televisão para produzir e transmitir sua programação no território, e os sistemas de ações com a criação de uma psicosfera, ${ }^{13}$ pois a televisão é um objeto técnico que pulveriza nos lugares imagens, valores, ideias, crenças e consensos através da programação local e nacional.

\section{A televisão é um objeto técnico} altamente difundido mundialmente, que surge no momento da transição do meio técnico para o meio técnico-científico e informacional ${ }^{14}$ e se impõe como o principal meio de comunicação das últimas décadas em todo o planeta - e no Brasil este objeto moderno assume vulto. Possui o maior alcance territorial do país, chega a praticamente todos os lugares e se coloca como o principal meio de comunicação da

12 "A tecnosfera se adapta aos mandamentos da produção e do intercâmbio e, desse modo, frequentemente traduz interesses distantes; desde, porém, que se instala, substituindo o meio natural ou o meio que a precedeu, constitui um dado local, aderindo ao lugar como uma prótese" (SANTOS, 1996, p. 204).

13 "A psicosfera, reino das ideias, crenças, paixões e lugar da produção de um sentido, também faz parte desse meio ambiente, desse entorno da vida, fornecendo regras à racionalidade ou estimulando o imaginário. Ambas - tecnosfera e psicosfera são locais, mas constituem o produto de uma sociedade bem mais ampla que o lugar" (SANTOS, 1996 , p. 204).

${ }^{14}$ Milton Santos postulou três principais períodos: o meio natural, onde "as técnicas e o trabalho se casavam com as dádivas da natureza, com a qual se relacionavam sem outra mediação"; o meio técnico, quando "os objetos técnicos, maquínicos, juntam à razão natural sua própria razão, uma lógica instrumental que desafia as lógicas naturais, criando, nos lugares atingidos, mistos ou híbridos conflitivos" e o meio técnico-científico e informacional, que "começa praticamente após a segunda guerra mundial e, sua afirmação, incluindo os países de terceiro mundo, vai realmente dar-se nos anos 1970", no qual "os objetos técnicos tendem a ser ao mesmo tempo técnicos e informacionais, já que, graças à extrema intencionalidade de sua produção e de sua localização, eles já surgem como informação; e na verdade, a energia principal de seu funcionamento é também a informação" (1996, p. 186-192). população, ao transmitir informações sobre o mundo, o país e, de maneira restrita, os lugares.

A ideia sobre o que possa ser 0 mundo e o lugar para a maioria dos brasileiros passa obrigatoriamente por este aparelho. ${ }^{15}$ Além disso, há o fato de que os meios de comunicação no país são controlados por poucas empresas e não há mecanismos democráticos de controle social sobre a veiculação da programação.

De acordo com dados do IBGE (Instituto Brasileiro de Geografia e Estatística), o televisor é o eletrodoméstico que permite o acesso à informação mais presente nos lares brasileiros, com 94,45\% em 2007. Em 1970, estava presente em 24,11\% dos domicílios e, em 1980, em $56,10 \%$ deles. Atualmente, depois do fogão, o televisor é o bem durável de maior importância para os brasileiros. Em pleno momento de conversão para o padrão de transmissão digital, ainda existem televisores em preto e branco no país (0,94\% em 2007).

Identificamos os principais eventos relacionados à implantação da televisão no Brasil através da geração de uma Matriz de Eventos, que relaciona os lugares onde surgiram emissoras da Rede Globo de Televisão com as possibilidades técnicas de cada momento. Com os dados desta matriz foram cruzados os dados do histograma das inaugurações de emissoras próprias e afiliadas, de 1965 a 2006, apontando para

\footnotetext{
15 " [...] a televisão brasileira é uma produtora de imagens que promovem, na imaginação do telespectador, a satisfação de um conjunto reprimido de desejos, ansiedades e esperanças decorrentes da própria frustração econômica, social e cultural de um país pobre" (FERRARA, 2002, p. 167).
} 
uma periodização da expansão da empresa no território brasileiro:

- A partir de 1965 - alcance territorial limitado: programação restrita à Região Concentrada.

- A partir de 1972 - ampliação do alcance territorial: início da operação por sistema de emissoras afiliadas.

- A partir de 1983 - Integração completa do território: início da transmissão via satélite para todo o Brasil.

Evidentemente não podemos atribuir somente à tecnosfera o aumento da área atingida pela programação da Rede Globo de Televisão, pois o tempo da técnica se completa com o tempo da norma e da política. Existem outros elementos, como a criação de normas, assim como a modificação delas em consonância com interesses diversos, como o favorecimento a políticos locais e motivos econômicos.

Neste terceiro período de expansão da Rede Globo de Televisão, o ano de 1997 apresenta um aumento expressivo, de dezesseis novas afiliadas na empresa, ${ }^{16}$ sendo cinco delas no estado do Pará, outras cinco em Rondônia e as demais nos estados do Piauí, Acre, Amazonas, Goiás, Espírito Santo e Paraná.

Aquele ano coincide com a aprovação da Lei 9.472/97 que desde 1995 estava esboçada num acordo com a UIT (União Internacional de Telecomunicações). Esta lei,

16 TV Alvorada do Sul, TV Liberal Altamira, TV Liberal Itaituba, TV Liberal Paragominas, TV Liberal Redenção, TV Liberal Tucuruí, TV Parintins, TV Cruzeiro do Sul, TV Ariquemes, TV Cacoal, TV Guajará-Mirim, TV Ji-Paraná, TV Vilhena, TV Rio Paranaíba, TV Gazeta Norte e RPC TV Imagem Noroeste. ao permitir a propriedade cruzada dos grupos de telecomunicações, ${ }^{17}$ reforça também o poder local dos "coronéis eletrônicos", uma vez que estes passam a controlar mais de um meio de comunicação.

Esta prática tornou-se possível por uma tradição política brasileira de concessões públicas (outorgas) dos canais de televisão aberta. Até 1988 a concessão era feita pelo próprio presidente da República, e após aquele ano (promulgação da Constituição) passou a ser feita pelo Ministério das Comunicações, a fim de moralizar o processo. São comuns as expressões "coronelismo eletrônico" e "latifúndio audiovisual" cunhadas por autores que analisam as concessões (CUNHA, 2004). A primeira refere-se à concessão de canais de rádio e televisão aberta para políticos e parlamentares, que fazem uso político-partidário do veículo, embora isto não seja permitido por lei no Brasil. A segunda seria uma consequência de essa "tradição" acabar concentrando as empresas de comunicações nas mãos de grupos $^{18}$ que também detêm poder político em quase todas as regiões brasileiras. Nos governos de José Sarney e Fernando Henrique Cardoso, as concessões serviram como troca de favores para aprovação do mandato presidencial de cinco anos e depois para a aprovação da reeleição, respectivamente (CAPARELLI, 2005).

O exame desta empresa de televisão no Brasil revela uma falta de controle estatal

\footnotetext{
17 "[...] em que um mesmo grupo detém diferentes tipos de mídia, isto é, a concessão de uma emissora de televisão e um jornal, por exemplo, ou uma revista e uma emissora de rádio [...]" (CUNHA, 2004).

18 "[..] ao mesmo tempo em que produzem um programa televisivo, por exemplo, possuem mecanismos para divulgá-los em jornais, produzir a trilha sonora em gravadoras próprias e tocá-la em emissora de rádio etc. [...]" (CUNHA, 2004).
} 
efetivo sobre os serviços de radiodifusão. Por outro lado, embora o controle estatal tenda a ser mais democrático, também não é garantia de ampliação da densidade comunicacional. De acordo com MartínBarbero (2006), a busca deve ser pela democratização do seu uso, visto que ativar somente instrumentos para seu controle burocrático não é suficiente. Para tanto, seria

\section{Legenda:}

1 TV Globo - Rio de Janeiro

2 TV Globo - São Paulo

3 TV Globo - Belo Horizonte

4 TV Globo - Brasília

5 TV Globo - Recife

6 Rede Integração Uberlândia

7 TV TEM - Bauru

8 RBS TV Blumenau

9 TV Sergipe - Aracajú

10 RBS TV Porto Alegre

11 RBS TV Caxias do Sul

12 RBS TV Erexim

13 RBS TV Pelotas

14 RBS TV Uruguaiana

15 TV Anhanguera Goiânia

16 TV Verdes Mares

17 TV Clube

18 TV Morena

19 TV Morena Corumbá

20 TV Centro América

21 RPC TV Cultura

22 RPC TV Paranaense

23 TV Liberal - Belém

24 TV Gazeta de Vitória

25 TV Gazeta de Alagoas

26 TV Anhanguera Gurup

27 RBS TV Bagé

28 RBS TV Rio Grande

29 TV Anhanguera

30 RBS TV Florianópolis

31 RBS TV Cruz Alta

32 EPTV Campinas

33 RPC TV Coroados

34 RBS TV Joinvile

35 TV Panorama

36 RBS TV Passo Fundo

37 TV Tocantins

38 EPTV Ribeirão Preto

39 RBS TV Chapecó

40 TV Rondônia

41 TV Acre

42 TV Roraima

43 TV Amapá

44 TV Tapajó

45 TV TEM S. J. Rio Preto

46 TV Amazonas

47 TV Cabo Branco

48 TV Paraíba

49 TV Bahia

50 Intertv Grande Minas

51 TV Mirante Imperatriz

52 TV Cabugi

53 TV dos Vales

54 TV Liberal Marabá

55 TV Gazeta Sul

56 TV Subaé

57 EPTV Sul de Minas

58 RBS TV Santa Cruz

59 TV Vanguarda

60 TV Santa Cruz
Rio de Janeiro - RJ

São Paulo - SP

Belo Horizonte - MG

Brasília - DF

Recife - PE

Uberlândia - MG

Bauru - SP

Blumenau - SC

Aracaju - SE

Porto Alegre - RS

Caxias do Sul - RS

Erexim - RS

Pelotas - RS

Uruguaiana - RS

Goiânia - GO

Fortaleza - CE

Teresina - PI

Campo Grande - MS

Corumbá - MS

Tangará da Serra - MT

Maringá - PR

Curitiba - PR

Belém - PA

Vitória - ES

Maceió - AL

Gurupi - TO

Bagé - RS

Rio Grande - RS

Araguaína - TO

Florianópolis - SC

Cruz Alta - RS

Campinas - SP

Londrina - PR

Joinvile - SC

Juiz de Fora - MG

Passo Fundo - RS

Anápolis - GO

Ribeirão Preto - SP

Chapecó - SC

Porto Velho - RO

Rio Branco - AC

Boa Vista - RR

Macapá - AP

Santarém - PA

São José do Rio Preto - SP

Manaus - AM

João Pessoa - PB

Campina Grande - PB

Salvador - BA

Montes Claros - MG

Imperatriz - MA

Natal - RN

Coronel Fabriciano - MG

Marabá - PA

Cachoeiro de Itapemirim - ES

Feira de Santana - BA

Varginha - MG

Santa Cruz - RS

São José dos Campos - SP

Itabuna - BA

preciso estimular práticas que conduzam ao uso democrático por parte da maioria da população. Pensamos que este papel caberia, por sinal, inclusive aos meios de comunicação de amplo alcance, mas estes estão há décadas garantindo a participação política somente para uma minoria da população abastada economicamente.

61 Rede Integração

62 TV Morena

63 RPC TV Cataratas

64 EPTV Central

65 Intertv Alto Litoral

66 TV Centro América

67 TV Balsas

68 TV Sudoeste da Bahia

69 Intertv Serra Mar

70 TV Riviera

71 TV Mirante Santa Inês

72 TV liberal Castanhal

73 TV São Francisco

74 TV Rio Sul

75 TV TEM Sorocaba

76 TV Oeste da Bahia

77 TV Mirante São Luis

78 TV Grande Rio

79 TV Asa Branca

80 TV Tribuna

81 Rede Integração Araxá

82 RBS TV Santa Rosa

83 RPC TV Esplanada

84 TV Fronteira

85 TV Rio Vermelho

86 TV Centro América SINOP

87 TV Mirante Cocais

88 RBS TV Criciúma

89 TV Anhanqueraas

90 TV Pirapitininga

91 TV Alvorada do Sul

92 TV Liberal Altamira

93 TV Liberal Itaituba

94 TV Liberal Paragominas

95 TV Liberal Redenção

96 TV Liberal Tucuruí

97 TV Parintins - AM

98 TV Cruzeiro do Sul

99 TV Ariquemes

100 TV Cacoal

101 TV Guajará-Mirim

102 TV Ji-Paraná

103 TV Vilhena

104 TV Rio Paranaíba

105 TV Gazeta Norte

106 RPC TV Imagem Noroeste

107 RPC TV Guairacá

108 TV Centro América

109 TV Liberal Parauapebas

110 TV Itacoatiara

111 TV Diário

112 RPC TV Oeste

113 TV TEM Itapetininga

114 TV Vanguarda Taubaté

115 TV Rio do Ouro

116 TV Rio Claro

117 Intertv Planície

118 RBS TV Centro Oeste

119 TV Gazeta Noroeste

120 TV Mirante Açailândia

121 RBS TV Santa Maria
Ituiutaba - MG

Ponta Porã - MS

Foz do Iguaçu - PR

São Carlos - SP

Cabo Frio - RJ

Rondonópolis - MT

Balsas - MA

Vitória da Conquista - BA

Nova Friburgo - RJ

Rio Verde - GO

Santa Inês - MA

Castanhal - PA

Juazeiro - BA

Resende - RJ

Sorocaba - SP

Barreiras - BA

São Luis - MA

Petrolina - PB

Caruaru - PE

Santos - SP

Araxá - MG

Santa Rosa - RS

Ponta Grossa - PR

Presidente Prudente - SP

Luziania - GO

Sinop - MT

Codó - MA

Criciúma - SC

Palmas - TO

Catalão - GO

Floriano - PI

Altamira - PA

Itaituba - PA

Paragominas - PA

Redenção - PA

Tucuruí - PA

Parintins - AM

Cruzeiro do Sul - AC

Ariquemes - RO

Cacoal - RO

Guajará-Mirim - RO

Ji-Paraná - PR

Vilhena - RO

Itumbiara - MG

Linhares - ES

Paranavaí - PR

Guarapuava - PR

Cuiabá - MT

Parauapebas - PA

Itacoatiara - AM

Mogi das Cruzes - SP

Cascavel - PR

Itapetininga - SP

Taubaté - SP

Porangatu - GO

Jataí - GO

Campos de Goytacazes - R

Joaçaba - SC

Colatina - ES

Açailândia - MA

Santa Maria- RS 
BRASIL: Emissoras próprias e emissoras afiliadas da Rede Globo de Televisão, 2008.

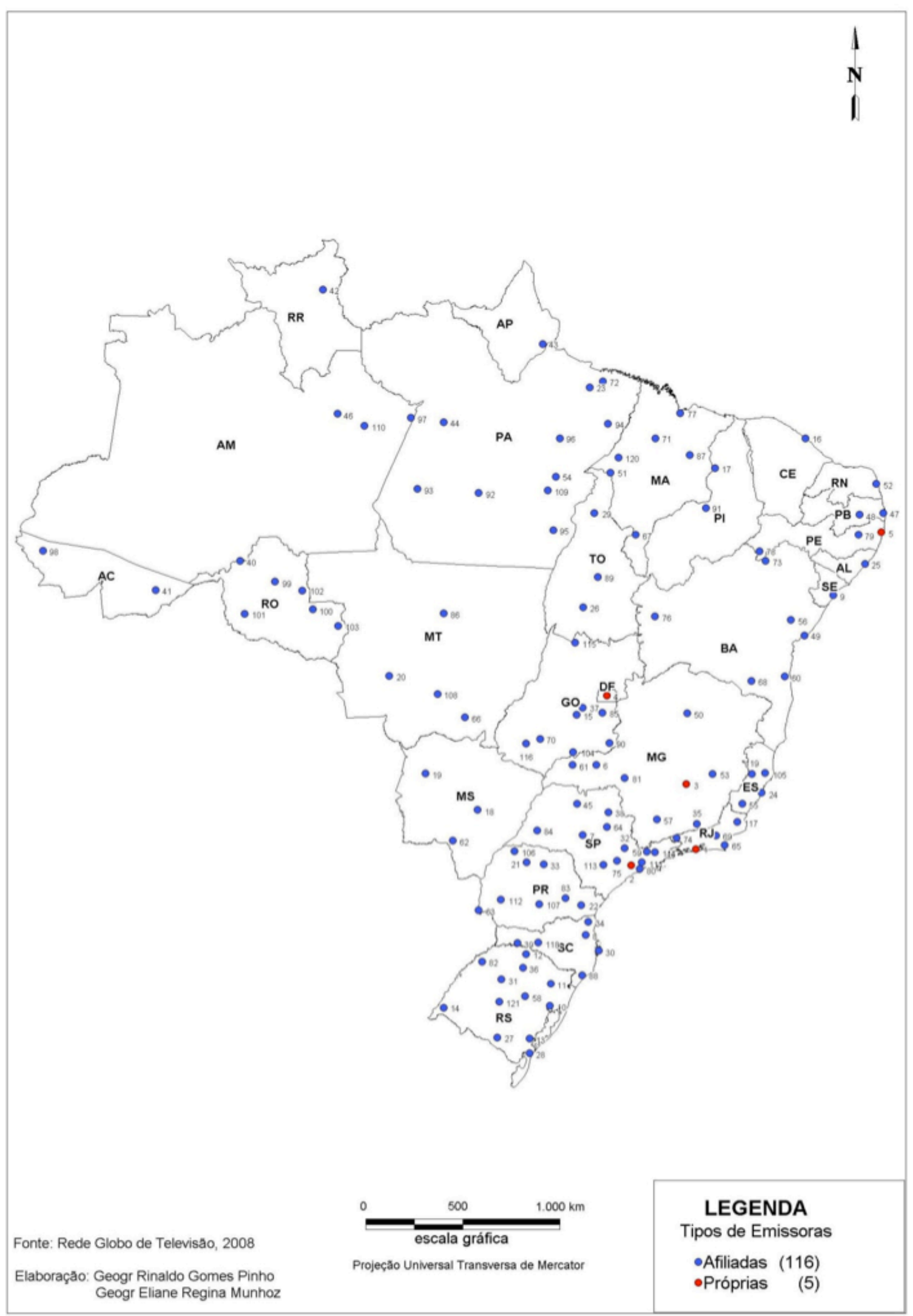




\section{A produção de "conteúdo"}

A tecnosfera necessária ao funcionamento dos sistemas de engenharia (torres de recepção e retransmissão, links de microondas, captação do sinal do satélite etc.) em consonância com uma psicosfera (ideologia do progresso que, muitas vezes, chegou ao lugar com o sinal da emissora nacional tradicionalmente reconhecida pela sua "qualidade") reorganizam os arranjos preexistentes nos lugares e impõem verticalmente uma lógica apropriada à sua instalação.

Tratamos de investigar o que as afiliadas produzem nos lugares onde se inserem, os chamados conteúdos locais. Para compreender o funcionamento do sistema de afiliadas, analisamos o processo de produção da programação local de quatro afiliadas da Rede Globo de Televisão no estado de São Paulo: TV TEM de Bauru, EPTV de Campinas, TV Fronteira Paulista de Presidente Prudente e TV Tribuna de Santos. As duas primeiras integram as principais redes de comunicação do estado, e as demais são emissoras isoladas, não pertencentes às redes até o momento.

O critério que norteou a escolha das afiliadas paulistas foi a contemplação de: afiliadas que produzissem "conteúdos locais" em rede; afiliadas que produzissem "conteúdos locais" sem pertencer à redes.

As afiliadas da Rede Globo de Televisão instalam-se nos lugares como retransmissoras da programação nacional, e como produtoras de programação local. Investem nesta produção com equipe própria, centrada basicamente no jornalismo, e com departamentos de marketing, comercial, de engenharia etc. Seu lucro é obtido através dos anúncios locais e na porcentagem da publicidade repassada pela Rede Globo de Televisão, à qual têm direito por contrato, pois o sistema de emissoras afiliadas está sob a lógica da comunicação de mercado.

A divisão territorial do trabalho promovida pela produção da programação da Rede Globo de Televisão estabelece uma hierarquia entre os lugares. O conteúdo nacional é produzido com a cooperação de duas emissoras próprias da empresa, a do Rio de Janeiro e a de São Paulo, e transmitido do Rio de Janeiro, via satélite, juntamente com os anúncios nacionais para as capitais de estado. Estas emissoras próprias não são consideradas produtoras de conteúdo local, pois o único programa que produzem fora da grade de programação nacional é o telejornal local. Ao chegar a programação nas capitais, é incorporada uma pequena programação estadual, além dos anúncios a ser veiculados em todo o estado. Nas emissoras afiliadas, geralmente 0 município com maior população e que concentra o potencial de consumo maior da área de cobertura, recebe via satélite (ou em alguns casos de falha no envio de sinal, via enlaces de microondas) o conteúdo nacional e estadual, com seus respectivos anúncios. É aqui onde são, finalmente, inseridos os programas locais.

A operação em rede das emissoras afiliadas da Rede Globo de Televisão mostra o direcionamento do fluxo de programação do Rio de Janeiro (que recebe via satélite de São Paulo parte da programação nacional) em direção à capital São Paulo e dali para os lugares abrangidos pela programação local das afiliadas (Mapa 2). Nota-se que este fluxo dá-se verticalmente. A contribuição de 
programações dos lugares para a emissora sede não segue este mesmo percurso.

De modo geral a programação veiculada pelas afiliadas é uma montagem de programações produzidas em vários lugares (Rio de Janeiro - RJ e São Paulo - SP programação nacional; capital do estado programação estadual; afiliada programação local). Isso só se tornou possível pela utilização de sistemas técnicos que racionalizam a produção, pois para utilizar todo o tempo e espaço da programação, se requer um controle minucioso do envio e recebimento instantâneo dos sinais entre as empresas.

Os programas locais das emissoras afiliadas analisadas foram classificados em seis tipos, de acordo com seu processo de produção: obrigatório; opcional da afiliada; opcional rede; opcional entre afiliadas; montagem e estadual.

As emissoras afiliadas que veiculam mais tempo de programas opcionais da afiliada são: a TV Tribuna, TV TEM Bauru e a EPTV, de Campinas, com 33,62\%, 18,98\% e
$18,73 \%$, respectivamente. Já a emissora que concentra a maior parte da produção em programas obrigatórios é a TV Fronteira Paulista, de Presidente Prudente, com $83,55 \%$. Se separarmos os programas em obrigatório (contratual) e não obrigatório (opcionais, em rede, montagem etc.), as emissoras afiliadas vinculadas às redes têm maior produção de programas não obrigatórios (TV TEM Bauru com 43,41\% e EPTV Campinas com 42,86\%), enquanto que as emissoras desvinculadas das redes de televisão produzem menos programas não obrigatórios (TV Fronteira Paulista de Presidente Prudente com 16,45\% e TV Tribuna de Santos com 38,33\%). Uma ressalva a fazer é sobre a TV Tribuna, de Santos, que produz mais tempo de programa opcional afiliada $(33,62 \%)$ que as emissoras vinculadas a rede. Isso, no entendimento do gerente de programação da emissora, Ipopovit Alves dos Santos, se deve à demanda da população do município de Santos, por ser participativa e cobrar representatividade perante a emissora, fato que destoa dos demais municípios.

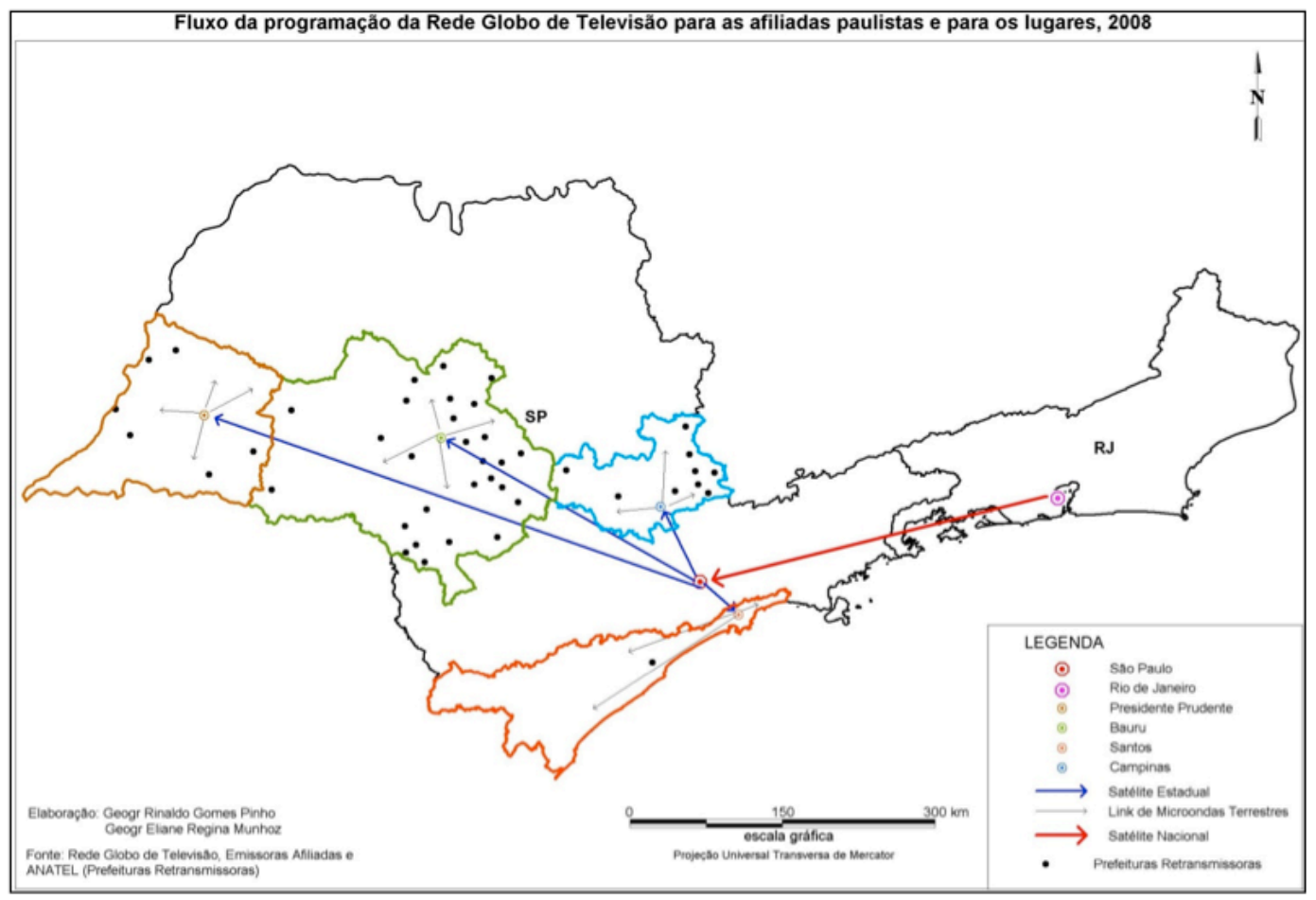


Nas quatro emissoras paulistas analisadas, 63\% da programação local (1.268 minutos semanais) veiculada é obrigatória, sendo os $37 \%$ (745 minutos semanais) restantes ocupados com conteúdo local não obrigatório.

Ao comparar o tempo da
programação nacional com o tempo da
programação local e o que é destinado à
publicidade, observa-se uma predominância
da primeira sobre a segunda (Gráficos 1 e 2 ).

\section{Gráfico 1}

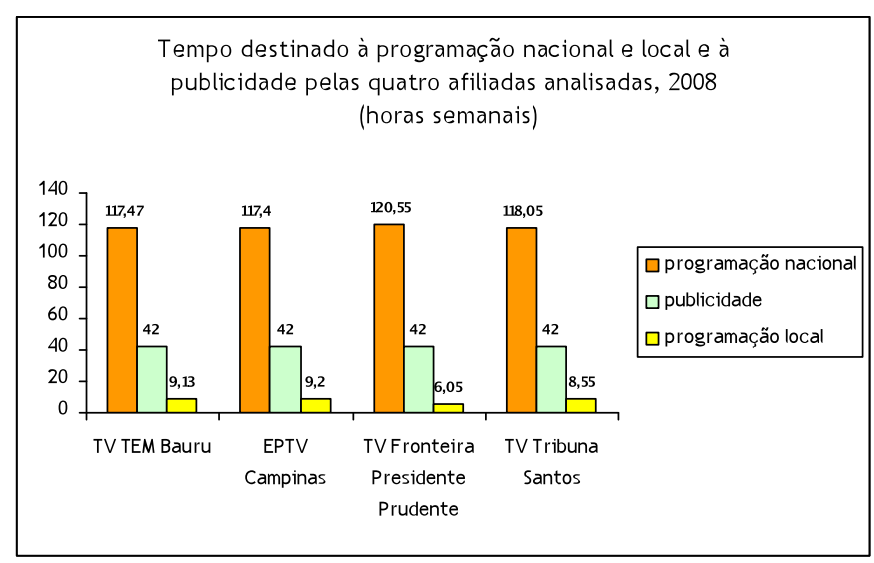

Fonte: Elaboração própria, de acordo com informações cedidas pelas emissoras afiliadas.

\section{Gráfico 2}

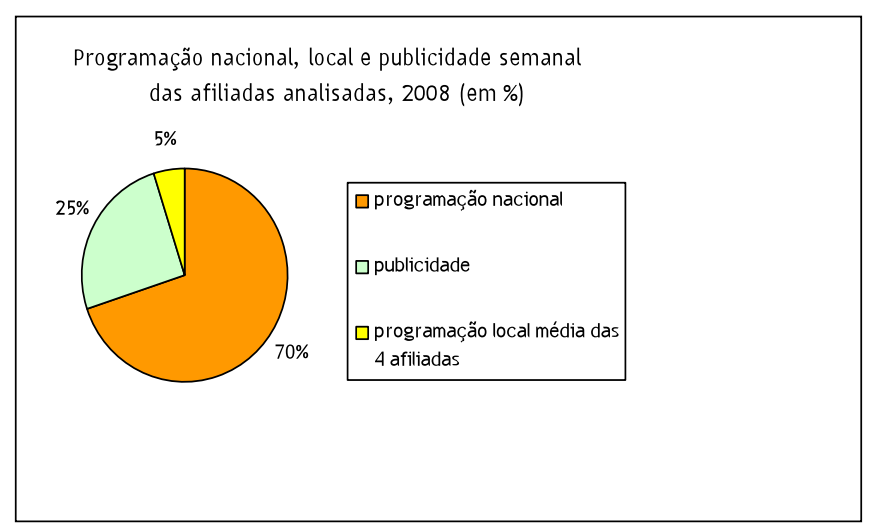

Fonte: Elaboração própria, de acordo com informações cedidas pelas emissoras afiliadas.

Em porcentagem e em horas semanais, respectivamente, o espaço destinado à programação nacional é de $70 \%$ que varia de 117 horas e 40 minutos da EPTV de Campinas a 120 horas e 55 minutos da TV Fronteira Paulista de Presidente Prudente; aproximadamente $5 \%$ à programação local ${ }^{19}$ (variando de 9 horas e 20 minutos da EPTV

\footnotetext{
19 No caso da TV Fronteira Paulista de Presidente Prudente, como não consideramos a parte da programação local comprada da EPTV, este percentual ficou inferior a $5 \%$.
}

Campinas a 6 horas e 5 minutos da TV Fronteira Paulista de Presidente Prudente) e $25 \%$ - no máximo - a publicidade, conforme estipulado por lei, o correspondente a 42 horas semanais.

Constata-se um baixo percentual de programação local produzida pelas emissoras afiliadas, inferior inclusive ao percentual reservado à publicidade, e dentre todos os programas locais, o único a ser exibido em horário nobre é o Jornal Regional segunda 
edição (quinze minutos às 19h). Os demais são em horário de menor audiência. De acordo com a Código Brasileiro de Telecomunicações de 1962, em seu artigo 38, letra $h$, ordena-se que:

As emissoras de radiodifusão, inclusive televisão, deverão cumprir sua finalidade informativa, destinando $5 \%$ (cinco por cento) de seu tempo para transmissão de serviço noticioso.

Constata-se que este percentual não é atingido pelas afiliadas analisadas, pois o total da produção local, incluindo os programas opcionais, é de $5 \%$ do total da programação.

Este quadro desenhou-se diante do uso das técnicas e normas contemporâneas, que impuseram ações verticais no território a serviço da empresa. A instalação da empresa Rede Globo de Televisão no território brasileiro beneficiou-se de uma série de normas do aparelho estatal (com a prática de lobbies) e criou diversas normas próprias para seu funcionamento e expansão. Para a empresa utilizar-se do território como recurso, ela oferece uma relação contratual sedutora para as afiliadas, cedendo sua programação nacional e pagando uma porcentagem dos contratos publicitários para exibir os anúncios nacionais nos lugares. Cabe às emissoras afiliadas explorar 0 mercado publicitário local e produzir um conteúdo local, mediante regras padronizadas para todas as 121 afiliadas da Rede Globo de Televisão. Uma das principais vantagens disso para a emissora é garantir a captação de imagens e reportagens produzidas pelas afiliadas sem necessitar deslocar equipes próprias para os lugares, pois diante das características continentais do Brasil isso encareceria a produção, dificultando sua viabilidade.

A normatização da empresa Rede Globo de Televisão deu-se inicialmente através do jornalismo. O PRODETAF possibilitou alcance nacional com a difusão das regras da produção jornalística, e atingiu toda a produção de conteúdos, nacionais e locais. O "padrão Globo" de qualidade é uma expressão ampla e vaga $^{20}$ utilizada pela empresa no que se refere ao apuramento das técnicas e das normas presentes na produção de sua programação, realizada com muito investimento.

A partir do momento em que os lugares são controlados por ações ordenadas distantes deles "o resultado é a aceleração do processo de alienação dos espaços e dos homens" (SANTOS, 1996, p. 217-218). Uma das consequências deste processo de alienação, de acordo com as palavras de Milton Santos, é que "a região deixa de ser produto de solidariedade orgânica localmente tecida para tornar-se resultado de solidariedade organizacional" (2005, p. 127).

A empresa Rede Globo de Televisão estabelece uma solidariedade organizacional na relação com suas emissoras afiliadas, pertencentes a "redes regionais" ou não, utilizando-se de normas rígidas. As emissoras locais por acatarem estas ordens deixam de criar suas próprias regras, baseadas nas necessidades do lugar. Além disso, inibe-se a criatividade, a valorização de outros tipos de programas e de outras formas de expressão.

\footnotetext{
20 De acordo com Daniela Campos Lourenço gerente de infraestrutura e desenvolvimento da Central Globo de Afiliadas, em entrevista de 13 agosto de 2007, a qualidade é o que dá a audiência da empresa.
} 


\section{O papel da publicidade na estratégia das afiliadas pelo território}

Os meios de comunicação no Brasil são financiados prioritariamente por anúncios publicitários, havendo também meios de comunicação subvencionados por entidades governamentais, de forma pontual. Lídia Antongiovanni (1999) caracteriza a atividade publicitária no período atual como: produtora de fluidez territorial, financiadora dos meios de comunicação e como difusora da comunicação.

Para a publicidade atingir com eficácia todos os lugares, a empresa utiliza de estratégias para conhecê-los. Os lugares se diferenciam em decorrência dos usos estabelecidos no território por diversos agentes e para tirar proveito também desta diferenciação são realizados estudos de mercado por empresas especializadas.

Neste caso, trata-se de um indicador elaborado pela empresa Target Marketing (criada em 1980), chamado de IPC Target Brasil em foco, para a Rede Globo de Televisão e demais empresas que necessitam de um levantamento detalhado do perfil de consumo dos brasileiros.

O território coberto pelas 121 afiliadas totaliza $100 \%$ do potencial de consumo, que é fracionado de acordo com as potencialidades de consumo locais, sendo que a cada emissora afiliada (com os municípios que compõem sua área de cobertura) corresponde uma parte deste índice. Vale lembrar que o índice não está só relacionado à quantidade de municípios cobertos pela emissoras afiliadas. A prestação de contas dos anúncios nacionais, estaduais e locais entre a afiliada e a rede é baseada neste indicador, de maneira proporcional ao valor da tabela de preços nacionais.

Com a normatização da tabela de preços das afiliadas pela Rede Globo de Televisão, aos lugares são atribuídos valores. Cada lugar recebe investimentos e produção de programação local de acordo com suas potencialidades de consumo.

Para potencializar a participação dos anunciantes, a emissora carioca fornece uma consultoria, denominada sugestivamente de "Mapa da Mina", cujas fontes utilizadas são: IBOPE, IBGE, projeções do Ministério da Agricultura e dados divulgados pela Agrishow - que está entre os três maiores eventos agropecuários do mundo. A base da argumentação é a visão de como explorar a economia dos lugares aproveitando-se de sua sazonalidade.

Trata-se de estudos, divulgados desde 1989, das culturas existentes no país, nos quais são indicadas as épocas de colheita dentro da área de cobertura de cada uma das 121 emissoras afiliadas, e os melhores momentos para se investir em publicidade.

\section{Entre o público e o privado: as prefeituras assumem a função de retransmissoras}

Como parte da consolidação da empresa Rede Globo de Televisão em mais de $99 \%$ do território brasileiro, verificamos o papel assumido pelas Prefeituras. Existem municípios que não recebem a programação da emissora por meio de rotas de microondas terrestres, e só podem recebê-la por intermédio de antenas parabólicas (que captam o sinal do satélite com a programação nacional, sem o "conteúdo 
local"). Com isso cria-se um ônus relativo à aquisição de tais antenas.

Para atingir estes lugares não atendidos pelas redes terrestres, a Rede Globo de Televisão, assim como as demais redes nacionais de televisão (Bandeirantes, SBT, Record etc.), utiliza-se de orçamentos públicos municipais: Prefeituras que instalam e fazem a manutenção de torres e antenas para retransmitir a programação. Essas antenas captam, via satélite, somente a programação nacional ou a estadual (a depender do meio natural); ou, através de sinal de microondas, a programação com conteúdo local da afiliada mais próxima. Então, retransmitem a programação para seus municípios e distritos. Para tanto, parte da arrecadação de pequenos e médios municípios brasileiros é destinada à aquisição de uma estação de retransmissão ${ }^{21}$ e sua respectiva manutenção.

São as chamadas RTVs (GÖRGEN, 2007) retransmissoras de televisão, aqui denominadas Prefeituras Retransmissoras. Este sistema complementar é capaz de levar a programação da emissora a lugares distantes do país dispensando investimentos privados, e está presente em todo o território brasileiro, concentradamente nas áreas onde o sistema de microondas terrestre não foi completado pelo Estado ou pelas redes de televisão.

\section{Quanto às afiliadas paulistas} analisadas, todas compartilham desta prática. A porcentagem de municípios cobertos pelas

21 "O custo de um posto de retransmissão mais simples, para localidades com até 10 mil habitantes, foi calculado pelo presidente da ABIRT (Associação Brasileira da Indústria de Radiodifusão), Eduardo Santos de Araújo, em R\$ 50 mil" (http://observatorio.ultimosegundo.ig.com.br/artig os.asp?cod=425ASP003). prefeituras retransmissoras é alta: TV TEM Bauru 25,00; EPTV Campinas 18,36; TV Fronteira Paulista Presidente Prudente 10,71 e TV Tribuna Santos 3,70.

\section{O lugar e as verticalidades trazida pela empresa: a criação da psicosfera da Modernidade e do progresso}

As bases do pensamento (e consequentemente da ação) ocidental contemporâneo estão no Iluminismo, contexto filosófico das formulações de Rousseau. Com os nobres ideais de busca da felicidade para a humanidade chegou-se à racionalidade, que, tendo o progresso como meta, imprimiu-se no mundo como ideologia. As relações sociais são fortemente marcadas pela ideologia do progresso, e, diante da impossibilidade do alcance deste por todos, vem sendo oferecido algo como uma espécie de compensação:

Naturalmente, a estratégia adotada para se lidar com as questões candentes da maioria de despossuídos foi colocar diante deles a miragem de uma possível aproximação do modelo ideal do "alto consumo de massa" norte-americano. Desse modo, a tarefa de superar o "subdesenvolvimento" no 'Terceiro Mundo' foi definida como simples "modernização" e convergência com os valores do "Norte democrático" (MESZÁROS, 2004, p. 137).

Esta face do capitalismo nos países subdesenvolvidos se apresenta na modernização ${ }^{22}$ tardia. A Modernidade surge como psicosfera no Brasil no bojo do processo de industrialização, que demandou

\footnotetext{
22 Distinguimos aqui modernização como processo de implantação de infraestrutura para a consolidação da industrialização brasileira e as variáveis decorrentes dele, e Modernidade como a psicosfera trazida com esse processo.
} 
uma série de investimentos públicos necessários para seu desenvolvimento como energia elétrica, transportes, comunicação. Tendo um papel fundamental para a aceitação desta modernização, a profusão dos meios de comunicação de amplo alcance trata de convencer a todos que era preciso progredir, pois as inovações são "produtores de condutas modernas" (MATTELART, 1996, p. 175). Passa a ser comum a expressão "chegada do progresso" para qualquer benfeitoria realizada com investimentos estatais.

Através dos dados sobre a existência de bens duráveis de 1970 a 2007, observa-se que houve uma primeira modernização dos meios de comunicação de amplo alcance no Brasil com o rádio ${ }^{23}$ (que chegava a 58,91\% dos lares em 1970, enquanto que a televisão atingia 24,11\%). $\mathrm{Na}$ década seguinte o televisor nas casas da população aumentava para 56,10\%, até que em 2001, com $89,05 \%$, superava o rádio $(88,05 \%)$, chegando a 2007 com 94,45\%. Enquanto isso, o rádio não registra aumento significativo, indo para $88,10 \%$.

Estas condições materiais oferecidas pela modernização com a instalação de uma tecnosfera (que ampliou desde as redes de suporte até o número de aparelhos de televisão), possibilitaram uma psicosfera de Modernidade a partir da programação televisiva brasileira, ao difundir ideias, valores e crenças pelos rincões do país, mudando a maneira pela qual as pessoas interagem com os lugares e criando uma hierarquia urbana reforçada pela empresa:

\footnotetext{
${ }^{23}$ O telégrafo e o telefone antecederam o rádio, e apesar de constituírem formas de comunicação à distância, não eram difundidos por todo o território e não se caracterizam como meio de comunicação de amplo alcance.
}

Legitimada pela ideologia do modernização cria, no território como um todo e em particular nas cidades, os equipamentos mas também as normas indispensáveis à operação racional vitoriosa das grandes firmas, em detrimento das empresas menores e da população como um todo (SANTOS, 2005, p. 114).

Para Dias (1996, p. 138) "a história da urbanização constitui, em grande parte, a história das redes técnicas". A concentração das ações de comando em certas partes do território se intensificou com o aumento da fluidez. "Hoje em dia se superpõem e se impõem os fluxos de informação - eixos invisíveis e imateriais certos, mas que se tornaram uma condição necessária a todo movimento de elementos materiais entre as cidades que eles articulam" (DIAS, 1996, p. 138).

A centralidade das duas metrópoles brasileiras na produção da programação nacional que é dirigida para todo o território estabeleceu-se em decorrência de uma herança, "de uma vocação industrial, que já se vinha revelando" antes do século $X X$ (SANTOS; SILVEIRA, 2001, p. 251). Dessa forma:

O eixo Rio-São Paulo desponta como
uma área de acumulação da produção
industrial, permitindo uma
diversificação da atividade fabril, que
beneficia igualmente os Estados da
região sul. Esse eixo industrial, capaz
de oferecer produtos mais variados e
mais baratos, afirma-se em
detrimento dos núcleos industriais
dispersos (SANTOS; SILVEIRA. 2001,
p. 251).

A polarização deste eixo se deu inicialmente em decorrência das atividades industriais. A globalização imprimiu novos usos a estes lugares, e "agora é a informação que ganha tal poder" (SANTOS; SILVEIRA, 
2001, p. 253). Da sede nacional no Rio de Janeiro, onde a empresa Rede Globo de Televisão foi inaugurada, e da sede de São Paulo, parte em tempo real a programação nacional da emissora. Cerca de $75 \%$ desta programação é realizada pela empresa, mas ela é deficitária na produção de desenhos animados e filmes, ${ }^{24}$ pois os compra de outros países. A forma pela qual esta programação chega aos lugares varia de acordo com as disponibilidades técnicas de cada momento, que determinam uma divisão territorial do trabalho caracterizando o uso que é feito do território pela empresa.

Até a chegada dos satélites de comunicações e seu uso pela empresa Rede Globo de Televisão, a programação era emitida do Rio de Janeiro para os lugares através dos links de microondas terrestres, e as cidades com maiores recursos e mais próximas à Região Concentrada conseguiam receber estes sinais com a instalação das torres. E os municípios com menos recursos situados entre estes pontos conseguiam ser atingidos pelos sinais, apenas colocando uma torre de recepção e um conversor para distribuição em UHF ou VHF. Essa tecnosfera revela uma densidade material propícia à expansão de uma certa divisão territorial do trabalho.

Atualmente, essa distribuição do sinal da programação da empresa Rede Globo de Televisão, fruto de uma racionalizada divisão territorial do trabalho, cria uma hierarquia urbana (Organograma 1).

\footnotetext{
${ }^{24}$ Durante o trabalho de campo fizemos algumas abordagens aos telespectadores, e uma reclamação comum foi a repetição dos filmes exibidos pela emissora.
}

Organograma 1 - Hierarquia urbana estabelecida pela distribuição da programação televisiva da Rede Globo de Televisão no território brasileiro

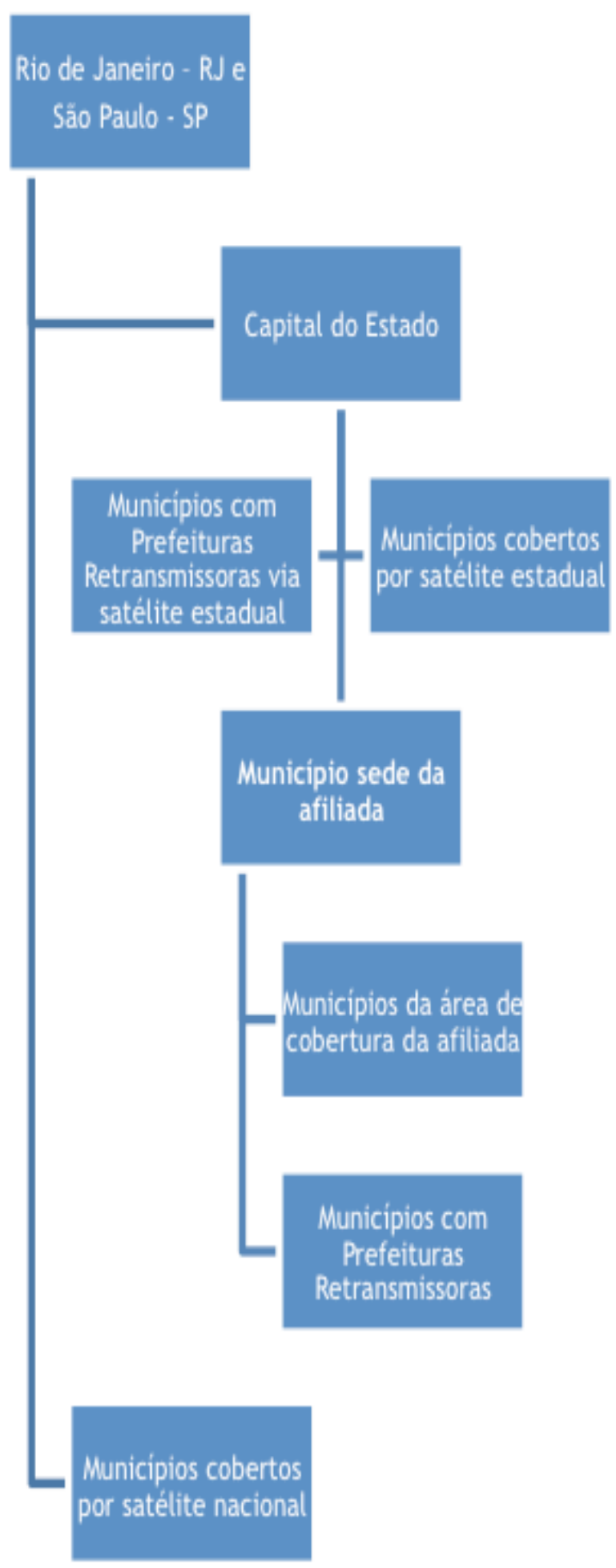

Fonte: Elaboração própria, a partir de informações da Rede Globo de Televisão e das emissoras afiliadas. 
Essa hierarquia é estabelecida em todo o território. Mas, em função das características dos lugares, a programação chega de forma diferente. Em lugares que contam com uma redundância de técnicas, a programação pode chegar através de links de microondas e/ou antenas de recepção do sinal do satélite com a programação estadual ou nacional, por pontos. Com as novas técnicas de transmissão da programação (satélites ponto a ponto), é possível romper se necessário - a hierarquia estabelecida anteriormente entre as cidades para levar o sinal.

$\mathrm{Na}$ realidade, a transmissão via satélite revela dois aspectos: ao mesmo tempo em que leva a programação nacional para as capitais de estados e destas para as afiliadas, leva também a programação como um vetor a outros lugares, onde não há viabilidade econômica para produzir um conteúdo local. A empresa reforça a hierarquia urbana com sua organização, acentuando as centralidades de algumas cidades.

As emissoras da Rede Globo de Televisão são financiadas pelos anúncios publicitários, oferecendo não só sua programação mas o próprio território como garantia de lucros.

Chegam até as afiliadas a programação nacional e a estadual (exceto nos casos em que a transmissão é feita via satélite, direto para o município) com espaços vagos para os anúncios locais (e para a programação local) a ser comercializados pelas equipes de marketing. Neste momento, a busca por anunciantes locais é feita de forma a preencher todos os espaços, pois um anúncio que deixa de ser veiculado é um capital desperdiçado, apesar de ser o tempo, nestes casos, aproveitado para o calhau, termo que designa a publicidade da própria emissora afiliada ou da Rede Globo de Televisão ou de outra empresa da família Marinho.

Para atrair os anunciantes são criadas estratégias, como a descrita por Mário Soler, sobre a TV TEM de São José do Rio Preto São Paulo:

O agendamento compulsório da pauta editorial pela agenda comercial ocorre em datas comemorativas, selecionadas previamente pela direção da emissora e pelo Departamento Comercial, para alavancar a venda de comerciais com apoio logístico da área editorial, mas pode se manifestar também em eventos criados pela própria emissora ou por ela apoiados. Embora os eventos tenham origem na pauta comercial do veículo, a redação dá a esses temas uma aura editorial, seja por imposição da direção, ou pela cultura dos selecionadores, considerando dignas de cobertura editorial certas datas e eventos voltados à exploração do marketing (SOLER, 2006, p. 107-108).

Então, para que a população tenha acesso ao telejornal local, deve-se aceitar o marketing atrelado à pauta de notícias, a fim de que a emissora se mantenha comercialmente de acordo com os padrões. Uma relação como esta é "naturalizada" pela psicosfera da Modernidade, já que é estabelecido que, sem estas empresas, o progresso não chegaria aos lugares.

Diante do quadro de concentração da posse dos meios de comunicação, e principalmente da baixa produção de programação local, em 2001 foi encaminhado à Câmara dos Deputados um projeto de lei 
256/91 para regulamentar o seguinte artigo 221 da Constituição Federal de 1988: ${ }^{25}$

\section{CAPÍTULO V}

\section{DA COMUNICAÇÃO SOCIAL}

Art. 221. A produção e a programação das emissoras de rádio e televisão atenderão aos seguintes princípios:

I. preferência a finalidades educativas, artísticas, culturais e informativas;

II. promoção da cultura nacional e regional e estímulo à produção independente que objetive sua divulgação;

III. regionalização da produção cultural, artística e jornalística, conforme percentuais estabelecidos em lei;

IV. respeito aos valores éticos e sociais da pessoa e da família.

De acordo com o estipulado pela Constituição de 1988, tanto o inciso II quanto o III referem-se à programação regional de rádio e televisão e devem ser regulamentados por lei específica a ser cumprida pelas emissoras brasileiras. A autora, na época a deputada, Jandira Feghali (PCdoB - Rio de Janeiro), elaborou um projeto de lei em que propõe um mínimo de $30 \%$ de programação local diária a ser cumprida pelas emissoras, o que foi prontamente rechaçado pelos grupos que as representam. Estes últimos negociaram com os demais segmentos uma porcentagem mínima de programação local, fora do "horário nobre", pois durante este período o tempo da publicidade é mais caro. ${ }^{26}$ Novas

\footnotetext{
${ }^{25}$ Constituição da República Federativa do Brasil de $1988 . \quad$ Disponível em: <http://www.planalto.gov.br/ccivil_03/constituicao /constitui\%C3\%A7ao.htm>. Acesso em: 12 jan,. 2008

26 "Das $18 \mathrm{~h}$ à meia-noite, o telespectador quer programação nacional, não quer ver buraco de rua", disse Marcello Petrelli, presidente da Associação Catarinense das Emissoras de Rádio e TV, referindo-se à programação local. Já a Rede Globo fez ressalvas ao projeto, pois esse tempo é
}

comissões foram formadas e foi elaborada nova redação, com alterações, para o projeto de lei.

O projeto foi submetido novamente à Comissão de Comunicação Social e discutido com entidades da sociedade civil, empresas, artistas e outros profissionais (ROLDÃO, 2006), dando origem ao PL 59/03, com algumas alterações do percentual de programação local/regional em função do número de domicílios atingidos pelas emissoras. Esse projeto estipula que, em localidades com mais de 1,5 milhões de domicílios com aparelhos de TV, a emissora teria que veicular programação regional por 22 horas semanais; entre $500 \mathrm{mil}$ e 1,5 milhão, uma cota de 17 horas; e nas regiões com menos de 500 mil televisores, 10 horas semanais. Deste tempo total destinado à programação local, $40 \%$ deveria ser reservado à "produção independente"27 sem fins comerciais.

Sabemos que as regras que normatizam internamente as afiliadas poderiam se desorganizar com a aprovação do projeto de lei. Para se reorganizarem, teriam que criar novas regras, adaptando-se à nova situação de forma que sua "natureza" comercial fosse preservada, até mesmo às custas de uma possível diminuição nos lucros.

praticamente o tempo ocupado pelas telenovelas e, entre as $18 \mathrm{~h}$ e $22 \mathrm{~h}$, a emissora cede às afiliadas apenas 15 minutos para o telejornal local (EPCOM. "Cota de programação local pode ser votada em 2002", 3 out. 2002).

27 "O presidente da Fundacine do Rio Grande do Sul acrescentou que o Brasil produz anualmente mais de cem filmes de longa-metragem e cerca de mil de curta-metragem, dos quais a maioria não encontra espaço na televisão brasileira". Artigo no FNDC, 7 nov. 2007: "Cristovam quer votar ainda este ano projeto que cria obrigatoriedade da produção local na televisão". Disponível em: <http://www.fndc.org.br/internas.php?p=noticias\& cont_key=203898 >. Acesso: 12 jan. 2008. 
Existem alguns obstáculos à regulação e à democratização dos usos dos meios de comunicação que se tornaram parte de uma cultura política brasileira. Rebouças (2006) analisa como os interesses do chamado "empresariado da mídia", como a Associação Brasileira de Emissoras de Rádio e Televisão (Abert), a Associação Brasileira de Radiodifusores (Abra), entre várias outras, se sobrepõem aos interesses dos demais atores sociais, e aponta para o discurso da "liberdade de expressão" como principal arma de defesa dos interesses privados.

Tudo o que possa criar empecilhos para as empresas de comunicação utilizarem o território brasileiro da forma que mais lhes convém é rechaçado por esse discurso, até mesmo o Conselho de Comunicação Social, ${ }^{28}$ vital para a realização da Reforma Comunicacional do Brasil.

Um outro aspecto da facilidade com a qual a desregulamentação regula o setor das comunicações é a confusão deliberada entre

\footnotetext{
${ }^{28}$ Sobre o Conselho de Comunicação Social, órgão consultivo do Congresso Nacional, "sua previsão consta do art. 224 da constituição e foi regulamentado pela lei 8.389/91. Apesar da criação, pela Constituição Federal, em 1988, e da lei regulamentadora, de 1991, o Conselho só foi efetivamente instalado em 2002, 14 anos depois de sua criação e 11 anos após sua regulamentação" (ZYLBERSZTAJN, 2008, p. 78).
}

os serviços públicos e os serviços privados. A própria rede de radiodifusão, um serviço público mantido e regulado pelo Estado por meio das concessões, é socialmente considerada, graças a construções ideológicas, propriedade das emissoras de televisão. $\mathrm{O}$ papel das Prefeituras Retransmissoras também ilustra a falta de clareza do serviço.

As redes de televisão brasileiras foram todas criadas pela iniciativa privada. Com poucas emissoras de caráter público, reconhecidas pela qualidade mas com pouco alcance, no Brasil emissora de televisão tornou-se sinônimo de empresa privada. Já na Europa, as primeiras emissoras de televisão foram iniciativas estatais, e até mesmo nos Estados Unidos, com o modelo de televisão privada do qual o brasileiro mais se aproxima, as emissoras públicas têm espaço efetivo garantido no sistema de radiodifusão.

Num país onde a comunicação não se efetiva como direito há décadas, e onde a regulação do uso dos meios de comunicação não se estabeleceu devido a interesses privados, torna-se imperiosa uma mudança na forma como ela está estabelecida. Enquanto esta mudança não ocorrer, qualquer outra de caráter social, que não atenda aos interesses das classes mais abastadas, continuará a ser boicotada.

\section{Referências bibliográficas}

ANTONGIOVANNI, L. L. 0 meio técnico-científico-informacional brasileiro: a publicidade como um vetor das modernizações. Dissertação (Mestrado em Geografia) - Faculdade de Filosofia, Letras e Ciências Humanas, Universidade de São Paulo, São Paulo, 2000.
CAPPARELLI, S.; SANTOS, S. Convergência das comunicações: dúvidas democráticas no cenário brasileiro In: LOPES, M. I. V.; BUONANO, M. (Orgs.). Comunicação social e ética: I COLÓQUIO BRASIL ITÁLIA. São Paulo: Intercom, 2005, v. 1, p. 336-355. 
CASTILLO, R. Sistemas orbitais e uso do território: integração eletrônica e conhecimento digital do território brasileiro. Tese (Doutorado em Geografia Humana) - Faculdade de Filosofia, Letras e Ciências Humanas, Universidade de São Paulo, São Paulo, 1999.

CHAUÍ, M. S. Simulacro e poder: uma análise da mídia. São Paulo: Perseu Abramo, 2006.

CUNHA, K. M. R. Televisão e política no Brasil, 2004. Disponível em: <http://www.cibersociedad.net/congr es2004/grups/fitxacom_publica2.php ?grup $=301 \& i d=444>$. Acesso em: 3 maio 2008.

DIAS, L. C. Redes eletrônicas e novas dinâmicas do território brasileiro. In: CASTRO, I. E. (Org). Brasil: questões atuais da reorganização do território. Rio de Janeiro: Bertrand Brasil, 1996.

FERRARA, L. D. O mapa da mina. Informação: espaço e lugar. In: SANTOS, M. (Org.). O novo mapa do mundo: fim de século e globalização. 4. ed. São Paulo: Annablume/Hucitec/Anpur, 2002.

GÖRGEN, J. Redes de televisão e prefeituras: uma dominação consentida, 2007. Disponível em: $<$ www.fafich.ufmg.br/compolitica/ana is $2007 /$ sc_pc-james.pdf $>$. Acesso em: 10 jan. 2008.

MARTÍN-BARBERO, J. Recepción de medios y consumo cultural: travesías. In: SUNKEL, G. (Org.). EI consumo cultural en América Latina: construcción teórica y líneas de investigación. 2. ed. ampl. rev. Bogotá: Convenio Andrés Bello, 2006, p. 47-71. (Colección Agenda Iberoamericana.)

. De los medios a las mediaciones. Bogotá: Convenio Andrés Bello, 2003.

MESZÁROS, I. O poder da ideologia. São Paulo: Boitempo, 2004.

ORTIZ, Renato. Outro território: ensaios sobre a mundialização. 2. ed. São Paulo: Olho d'Água, 2000.

REBOUÇAS, E. Estratégia retórica dos "donos" da mídia como escudo ao controle social. Líbero, ano IX, n. 17, jun. 2006. Disponível em: <www.facasper.com.br/pos/libero/lib ero15/04_edgard.pdf $>$. Acesso em: 26 ago. 2008.

RIBEIRO, A. C. T. Matéria e espírito: o poder (des)organizador dos meios de comunicação. In: PIQUET, R.; . Brasil, território da

desigualdade: descaminhos da modernização. Rio de Janeiro: Jorge Zahar/Fundação Universitária José Bonifácio, 1991. p. 44-55.

ROLDÃO, C. G. Regionalização da programação: boicote empresarial é explicitado no Conselho de Comunicação Social. ENCONTRO DOS NÚCLEOS DE PESQUISA DA INTERCOM, 6, Brasília, set. 2006.

SANTOS, Milton. A urbanização brasileira. 5. ed. São Paulo: Edusp, 2005.

. O retorno do território. In: SOUZA, M. A; SILVEIRA, M. L. Território: globalização e fragmentação. 5. ed. São Paulo: Hucitec, 2002.

A natureza do espaço: técnica e tempo, razão e emoção. 3. ed. São Paulo: Hucitec, 1996.

; SILVEIRA, M. L. O Brasil: território e sociedade no início do século XXI. Rio de Janeiro: Record, 2001.

SCORSIM, E. M. Estatuto dos serviços de televisão por radiodifusão. Tese (Doutorado) - Faculdade de Direito, Universidade de São Paulo, São Paulo, 2007.

SILVA, A. M. B. As grandes empresas de consultoria, a produção de informações e os novos círculos de cooperação no território brasileiro. Encontro de Geógrafos da América Latina, 10, 2005, São Paulo. Anais do X EGAL. São Paulo, v. 1, p. 1-15, 2005.

SILVA, C. A. Cidade, informação e cultura: a inserção do mercado de filmes em videocassetes no espaço urbano brasileiro. In: SANTOS, M. (Org.). 0 novo mapa do mundo: fim de século e globalização. 4. ed. São Paulo: Annablume/Hucitec/Anpur, 2002. 
SOLER, M. N. A. Quem pauta a pauta: rotinas produtivas do Tem Notícias primeira edição. Dissertação (Mestrado) - Faculdade de Arquitetura, Artes e Comunicação, Universidade Estadual Paulista Júlio de Mesquita Filho, Bauru, 2005.
ZYLBERSZTAJN, J. Regulação da mídia e colisão entre direitos

fundamentais. Dissertação

(Mestrado) - Faculdade de Direito, Universidade de São Paulo, São Paulo, 2008. 